\title{
SHARED ACCOMMODATION: CURRENT STATE AND POSSIBILITIES OF ITS DEVELOPMENT ON THE ISLAND OF MADEIRA
}

\author{
Petr JANEČEK ${ }^{1}$; Alena PUCOVÁ ${ }^{2}$ \\ ${ }^{1}$ University of West Bohemia, Faculty of Economics, Czech Republic \\ ${ }^{2}$ University of South Bohemia in České Budějovice, Faculty of Economics, Czech Republic
}

\begin{abstract}
:
Purpose: The aim of the paper is to analyse the current state and identify the potential for the development of shared accommodation in Madeira Island. Next goal is to identify barriers of its development based on the results of research about this type of accommodation and reduce them.

Design/methodology/approach: The literature review offers the basic understanding about information about sharing economy, but bigger focus is then on shared accommodation. The literature review also targets on the regulation of AirBnB in the world and the situation with AirBnB in the world. The research itself was divided into two sections. The first section is based on online questionings and the second on individual interviews. Online questionnaire survey is split up into two parts, the first part is focused on visitors from all over the world, who use shared accommodation, trying to find out, how travellers evaluate this specific type of accommodation and the second part is focused on providers of shared accommodation on the island of Madeira. To find out more opinions about shared accommodation, 10 individuals were approached. The individuals were asked questions, which were similar to the first survey, but more in depth. Respondents were asked for reasons and any thoughts about AirBnB. The data from both surveys were processed in program PSPP and Microsoft Excel.

Findings: Based on questionnaires it turned out that in many ways, answers of demand and supply are similar. Most respondents found out about AirBnB on the internet, the majority of both groups think that AirBnB is better than hotels and that AirBnB helps to develop tourism in the area but also that AirBnB is turning mainly into businesses and does not meet the main purpose of shared accommodation. The results also show that people are greatly influenced by reviews and without them, the chance of booking the accommodation is getting lower. Other answers indicate that most visitors prefer separated accommodations and most providers provide the entire homes with full privacy, so it collaborates very well. The research did not show significant difference in answers between genders.

Respondents of demand shared their negative experiences such as noise, smell, not good communication with the host, not clean place but also positive experiences such as a little gift, clean place, reasonable price, kind host etc. The negative findings were recorded as barriers of the development and some tips how to improve their offer were suggested to providers, Tips how to behave when choosing and staying in AirBnB were also suggested to visitors. Individual interviews helped to understand why people prefer AirBnB rather than hotels and it is mostly because of privacy, the kitchen area and the unique experience. Research limitations: The biggest limit is the focus on local environment of Island of Madeira that could be specific then overall worldwide environment. The second limit is based in research methodology. It was used online survey and research sample is limited (157 users and 30 providers of shared accommodation). The last limitation is time of research. The conditions of tourism and also shared accommodation are very influenced by COVID-19 pandemic.
\end{abstract}

Key words: AirBnB, shared economy, shared accommodation, Madeira Island Jel code: Z31, Z33,

https://doi.org/10.11118/978-80-7509-820-7-0405 


\section{Introduction}

In the 21st century, people are used to travel as never before. Thanks to globalization, ability to speak foreign languages, especially English, it is easy to visit places that our older generation could just dream about. The trend living like local is becoming more and more desirable and platforms for shared accommodation seem to be a way, how to achieve this desire. The segment of sharing economy starts to significantly change the accommodation market and attract the attention of regularoty authorities and entrepreneurs. (Krajcik, Kljucnikov \& Rihova, 2019) It is not all about shared accommodation but about sharing economy in general. People want to share cars, bikes, tools and so one. This paper is focused on shared accommodation, the research itself is focused just on AirBnB.

The aim of the paper is to analyse current state and identify the potential for the development of shared accommodation in Madeira island. Next goal is to identify barriers of its development based on the results of research about this type of accommodation and reduce them. At the beginning there is providing information about the area of research, Madeira, and all the assumptions mentioned in the paragraph above. Next, the paper continues with the research. The research itself was divided into a few sections. The first section was based on online questionings and the second on individual interviews. Online questionnaire survey was split up into two parts, the first part was focused on providers of shared accommodation on the island of Madeira, and the second part was focused on visitors from all over the world, who use shared accommodation. The base of individual interviews was similar to the questionnaire for visitors, but it was directed more in-depth.

\section{Literature review}

Sharing economy, also known as peer-to-peer based sharing, is a concept that emphasizes ability and preferences of people who prefer to rent or borrow something instead of owning things. This type of sharing became a trend at the turn of the $21 \mathrm{st}$ century.

People have always exchanged goods or services but nowadays thanks to technologies and free information, there is a new market model. There are three forces that started this model - modern trust, technologies and economic pressure. (Siuskaite, Pilinkiene, \& Zvirdauskas, 2019) Modern trust - the concept of sharing economy depends on something that previously seemed foolish or unthinkable, trust. People rely on other people cars (e.g. Uber), welcome strangers into their homes (e.g. AirBnB, Homeaway) or lend their belongings to the strangers. (Stemler, 2016) For someone, it might seem inconceivable to let strangers stay in your place or to accommodate yourself by strangers, but surprisingly, it works very well. Technology - technology is necessary for the development of the sharing economy in three ways - free information, lower transactions costs and it regulates behaviour. In the 21 st century, many people have access to the internet (2018, $55 \%$ of the population), (Statista, 2019) and it is incredibly easy to contact someone when you have free bedroom or spot in a car. Thanks to high-speed internet and lower costs of 
smartphones (the average price of smartphones is $250 €$, (GfK Czech Republic, 2017).

Economic pressure - economic pressure greatly participated in the formation of the sharing economy. Many of the sharing economy companies were founded between 2008 and 2010, in the aftermath of the global financial crisis. In this time, people were looking for different ways to save money and for ways how to make money. "With fewer full-time jobs, Americans were forced to take temporary work, and the sharing economy provided many sources of temporary jobs." (Stemler, 2016) Sharing economy surrounds all of us and sometimes we do not even know about that. Most known is probably apartment renting or car sharing, but sharing economy appears in more and more fields today. We can find the elements of the sharing economy in knowledge and talent-sharing, peer-to-peer lending, reselling and trading, co-working or even healthcare. (Sundararajan, 2016)

The principle of shared accommodation is known for many years, when people share their living with people that are not family members. The reason for this type of living is growing rents and basically unaffordability to rent for example whole apartment. The majority of people who live like this are single, mostly young people, for example students. (Heath, Davies, Edwards, \& Scicluna, 2017) However, shared accommodation on which this paper focused, has different principle. Modern shared accommodation is mostly short-term, for holiday rent, business trip etc. Sharing economy in general experienced rapid growth in the past five years and expressly shared accommodation is growing due to demand preferences changes. Travelers prefer to organize their own program, they are not seeking for support of travel companies and they like the benefit of the apartment, feeling like being at home. (Surugiu, Surugiu, \& Mazilescu, 2019) Rapidly grown sharing platform Airbnb brings many benefits not only to the customers, but also to the cities, by attracting more tourists and bringing financial and economic benefits, but unfortunately at the same time imposes the quality of life of the local citizens, influences housing and hotel markets. (Krajcik, Kljucnikov \& Rihova, 2019; Chamusca at al., 2019) The impact of Airbnb is not equally in each part of countries and also cities. According to Hübscher et al (2020) there is strong concentration of Airbnb listing in the centres. Short-term rentals become more attractive even in peripheral districts where rents increase and flats are taken off the traditional rental market. This will lead to new conflicts in the city because the peripheral districts are more vulnerable from a socioeconomic point of view.

AirBnB is probably the most famous portal for sharing accommodation. The company was founded in 2008 by schoolmates, Brian Chesky, Joe Gebbia and Nathan Blecharczyk. The company is headquartered in San Francisco, California and currently has about 3100 employees. "Airbnb's mission is to create a world where people can belong through healthy travel that is local, authentic, diverse, inclusive and sustainable." AirBnB offers more than 5 million places to stay, operates in more than 81000 cities in 191 countries in the whole world. The access to the service is via the website and mobile app. (Airbnb, 2018) Largest Airbnb cities outside of the US are Paris (47 000 places), London (31 000), Rome, Rio de Janeiro, Barcelona, all about 19000 places, Copenhagen (15 000), Milan (14 000), Sydney and Amsterdam 
(13 000). The most money makes hosts in London, Dubai, Zermatt, Cannes, Venice and Sydney and the cheapest accommodation can offer Salvador, Havana, Sarajevo, Bucharest, Sochi and Sofia. The highest AirBnB demand is in Tokyo, Melbourne, Osaka, Vancouver, Lisbon, Berlin and Amsterdam. (Shatford, c2015-2018) Booking home on AirBnB is very simple. Guests can search for a place using filters such as size, location, price and dates. Before booking, personal and payment information is necessary to provide to the host and after that, a person just has to wait for the message of acceptance. Hosts choose which dates they would like to accommodate someone and then it is time to wait for guests.

While some people really love the idea of AirBnB, AirBnB is becoming a quite controversial topic to discuss. For tourists, the idea of cheaper accommodation might sound phenomenal, but for people who live in the cities such as Amsterdam, Berlin or others often visited, AirBnB is becoming a bit a nightmare. The prices of apartments are growing rapidly fast, AirBnB owners sometimes do not pay taxes, especially young tourist on holiday might be loud, so having an apartment next to the AirBnB place might not be very pleasant. (Heckman, 2017) There is not only AirBnB, but there are many platforms for sharing accommodation e.g. Couchsurfing, Flatio, Flatmates.com, HomeAway etc. We consider that AirBnB is the biggest provider of sharing accommodation. Some big problems are identified with this and because some states development new roles for sharing accommodation. Through the last few years, the main concept of AirBnB has changed greatly. It is not only about offering spare place anymore, it has become a huge business opportunity. That causes a problem for many cities. People choose to rent their property through AirBnB because of bigger income rather than renting the property to locals. Some cities have already decided to regulate renting because basically, locals do not have a place to stay anymore, e.g. San Francisco, Berlin, London, Amsterdam, Barcelona, Prague etc.

\section{Methodology}

The aim of the paper is to analyse current state and identify the potential for the development of shared accommodation in Madeira island. Next goals are to identify barriers of its development based to reduce the negative impact and barriers connected to this type of accommodation. For the research was the research question developed. How is the difference between origin of sharing accommodation and current state of it? This question need to be studied more in detail. Partial questions are focused on both supply and demand side of tourism market in Madeira island.

The first step was the study of theoretical background and elaboration of literature review based on printed publications, web portals and professional publications. In the beginning is the literature review related to sharing economy in general, than more specifically in shared accommodation.

The next step focuses on quantitative research, that consist of two kinds of survey, interviews, the analysis of data and suggestions for owners that offer places through AirBnB. 
The first survey was aimed to the visitors, to find out, how travellers evaluate this specific type of accommodation. The number of respondents that were engaged in data collection was 157 . The questionnaire was shared mostly through social media, through Google Form, because the aim was to gain as many different cultures as possible. At the end of the research, people from 40 countries were engaged, $68 \%$ women and $32 \%$ men.

The second survey was focused on providers of accommodation that offer place on Madeira island. This segment was much smaller, so the number of questionnaires was estimated to 30. It is impossible for researcher who does not have access to details of AirBnB to find out the exact number of home providers. The number of listing in Madeira is about 5000, but some properties are owned by the same person or even a company, so the exact number remains a mystery. Owners were contacted through AirBnB portal. The gender representation was $47 \%$ women and $53 \%$ men.

The structure of both surveys was very similar. The questionnaire included openended and closed-ended questions, obviously demographic questions and also Likert scale questions.

The data provided by questionnaires were collected in the year 2018 and the beginning of the year 2019. The data from both surveys were processed in program PSPP that enable to sort the data and to make contingency tables. For the graphical representation, Microsoft Excel was used. To find out more opinions about shared accommodation, it was communicated with 10 individuals. The individuals were asked questions, which were similar as in the first survey, but more in depth. Respondents were asked for reasons and any thoughts about AirBnB.

\section{Results}

Madeira is very open to shared accommodation, on the 18th of April 2018, there were 4,604 rentals including Porto Santo with 110 rentals. The picture one shows the dissemination of shared accommodation on the island. The visitor can choose an entire home, private room (shared common areas) or shared room (with someone else). The most extended offer is to rent the entire home (4 220 rentals, 92\%). There are 350 private rooms (7\%) and only 34 shared rooms (1\%). Each rental has a different size. The most common rental (entire home) is with two bedrooms $(32,5 \%)$ and one-bedroom $(32,5 \%)$, the others $(35 \%)$ - studio $2 \%$, three-bedroom $22 \%$, more bedrooms $11 \%$. Price of the rental obviously depends on the choice of visitor (entire house, only room etc.). The average pricing for entire home is $58 €$, private room 37 $€$ and shared room $16 €$. The month, which generates the most revenue per available rental, is August, followed by July and September. The second half of January and the first half of December are the weakest parts of the year. During March 2018, 2 221 rentals had at least one booked night. That means that the occupancy was $55 \%$. Naturally, the most rentals are in the capital, Funchal, but whole south seaside is full of rentals. In the north there are rentals only in bigger cities such as Porto Moniz, Sao Vicente, Santana or Porto da Cruz. (AirDNA, c2015-2019) 


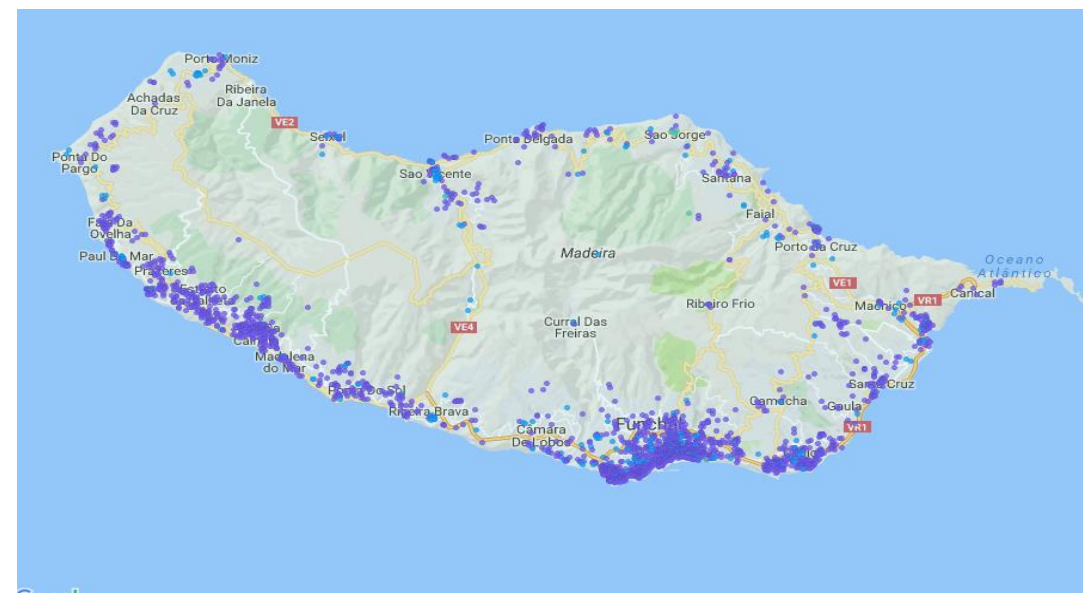

Figure 1. Map of AirBnB, Madeira

Source AirDNA, 2019

The number of rentals is growing rapidly fast. In 2010 there were only 3 rentals, in 2014 already 624 rentals and in 2018 4,604 rentals. That means annual growth of $59 \%$.

According to AirDNA (c2015-2019) most people (25\%) are booking their accommodation for more than 3 months in advance. $23 \%$ of reservations were made 31-60 days in advance, $15 \%$ of reservations were done less than one week in advance. On average, people are booking their accommodation for 66 days in advance.

On the 18th of August 2019, the number of active rentals was 5,292. The structure of rentals remains similar. The most extended offer is still to rent the entire home $(92 \%)$. There are $7,7 \%$ of private rooms and only $0,3 \%$ of shared rooms. Size of rentals and seasonality remain the same as in 2018. Prices stayed nearly the same as in 2018, except the price for entire home, which has risen from $58 €$ up to $70 €$. The price for private room is $34 €$ and $15 €$ for shared room. The occupancy rate has increased from 55\% to 65\%. Most visitors that came to Madeira in august 2019 were from London. $97 \%$ of all visitors are international and the number of arrivals in June 2019 was 2,352. The biggest website for booking accommodation online (Booking.com, 2019) offers over 2,500 places in Madeira, including 1170 apartments, 164 hotels and 625 holiday homes. From this information it seems that AirBnB offers more places to stay, but it is not possible to find exact numbers, because often Booking.com and AirBnB.com offer the same places on their sites.

Booking time has changed, more visitors are booking the rental more ahead. In 2018 only $25 \%$ of people were booking rental more than 3 months in advance, in 2019 the number increased to $45 \%$.

In the table 1, we can see a comparison in years 2018 and 2019. The biggest differences are in pricing of entire home, which has risen by $20 \%$, on the other hand, prices for private and shared room has decreased by ca $8 \%$. As was already mentioned above, the number of rental has risen, specifically by $15 \%$. The biggest 
difference was however in number of shared rooms. The number has decreased by unbelievable $50 \%$.

Table 1. AirBnB comparison in time

\begin{tabular}{|l|l|l|l|}
\hline Period & April 2018 & August 2019 & Results \\
\hline Pricing & $58 €$ & $70 €$ & $+20 \%$ \\
\hline Entire home & $37 €$ & $34 €$ & $-9 \%$ \\
\hline Private room & $16 €$ & $15 €$ & $-7 \%$ \\
\hline Shared room & $55 \%$ & $65 \%$ & $+18 \%$ \\
\hline Occupancy & 4604 & 5292 & $+15 \%$ \\
\hline Number of rentals & 464 & 4850 & $+14 \%$ \\
\hline Entire home & 4220 & 425 & $+21 \%$ \\
\hline Private room & 350 & 17 & $-50 \%$ \\
\hline Shared room & 34 & &
\end{tabular}

Source AirDNA, 2019

\section{The analysis of demand}

At the beginning of the research, respondents were asked where they found the option of accommodation with AirBnB. Most frequent answers were the internet with $49 \%$, the next was a friend with $31 \%$, social media with $15 \%$ and $5 \%$ of respondents have chosen the other option. We can see the difference between ages especially with the answer social media, nobody older than 50 years has answered this source. The answer social media was mostly recorded from respondents within 21-30 years, specifically 17 respondents.

The next question focuses on the year of becoming a member of the AirBnB community. This style of travelling is still quite young, many people joined the community just a few years ago. The most answered year was 2016 with 39 responds, 2017 and 2018 with 28 responds. Only 7\% of respondents joined the community earlier than in 2013. In comparison between genders, we can see that the most females joined AirBnB in 2016 (28 females), meanwhile most males joined AirBnB one year earlier, in 2015 (11 males).

The table 2 shows the reason for joining the community. The majority answered "Cheaper accommodation" with 70\%. 14\% respondents chose "other" that includes local experiences, bigger accommodation than just a hotel room, accommodation with a kitchen and living room, options for travelling with a group, residential neighbourhood. Another $12 \%$ chose "I wanted to try something new" and almost $5 \%$ wanted to meet more locals. The most students choose AirBnB for cheaper accommodation, the same choose workers, but workers have bigger impact in section "I wanted to try something new.", meanwhile students do not. 
Table 2. The reason for joining the AirBnB community according to the status of respondent

\begin{tabular}{|l|c|c|c|c|c|c|c|c|}
\hline & \multicolumn{2}{|c|}{ Student } & \multicolumn{2}{l|}{ Worker } & \multicolumn{2}{l|}{ Self-employed } & \multicolumn{2}{l|}{ Retirement } \\
\cline { 2 - 11 } & Abs. & $\%$ & Abs. & $\%$ & Abs. & $\%$ & Abs. & $\%$ \\
\hline Cheaper accommodation & 45 & 82 & 48 & 72 & 11 & 52 & 4 & 36 \\
\hline I wanted to try ... & 5 & 9 & 10 & 15 & 3 & 14 & 2 & 18 \\
\hline Meeting locals & 1 & 2 & 4 & 6 & 1 & 5 & 0 & 0 \\
\hline Other & 4 & 7 & 5 & 7 & 6 & 29 & 5 & 45 \\
\hline
\end{tabular}

Source: Own elaboration, 2019

The next question focus on the frequency of using AirBnB. 43,9\% of visitors use AirBnB only 1 time per year, 37,6\% 2-3 times per year, 11,5\% 4-5 times per year. We can guess that majority of respondents use AirBnB for the bigger holiday, which are commonly one time per year.

Preferences about host's gender are: $83 \%$ do not mind about gender, $15 \%$ prefers female as a host. We can assume that it is because in most cases, there is separated accommodation and the contact with the host might be very small. However, when someone prefers a gender of the host, it is mostly the case that woman prefer woman rather than man as a host.

In the figure 2, we can see the preferences about separated and shared accommodation. The results are quite a one-sided, most people would rather choose separated accommodation (88\%) than sharing the place with the host (12\%). This might be a little surprising, because one of the main purposes of AirBnB is to live like local and meet locals that is easier when you live in the house with one.

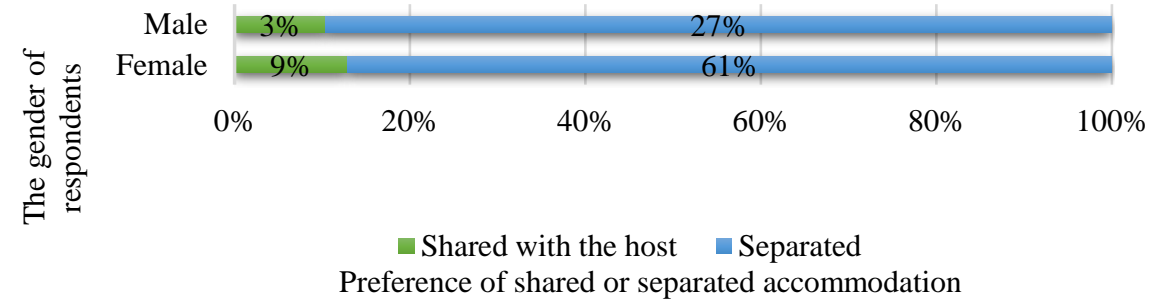

\section{Figure 2. Guest's preferences about type of accommodation}

Source: Own elaboration, 2019

The majority of respondents $(96,2 \%)$ do care about reviews and only $3,8 \%$ do not. The next question about reviews was asking if people would accommodate themselves in a room without review, $47,1 \%$ would not, $19,1 \%$ would, and the rest is not sure. The last question in this review set was asking if people would accommodate themselves in a room with bad review, 13, 4\% would and $86,6 \%$ 
would not. In comparison between genders, that more males are willing to accommodate themselves in a room with bad review and thereby give a host a second chance.

The aim of this shorter block was to find out positive and negative experiences. The question was asking if people have a negative experience with AirBnB and the answers were about even, $53 \%$ of respondents did not face any negative experience so far, $47 \%$ did.

The negative experiences are mostly smell, noise, dirty place or host who does not speak English, then the cat in the house without warning, keys that did not work, flat above noisy pub, fake pictures, not so professional approach of the host, high service fees and lack of support from the company. On the other hand, visitors also have positive experiences such as a box of chocolate or fruits as a welcoming surprise, nice talkative hosts, pleasant accommodation, cheap price, cleanliness, meeting wonderful people, home feeling, privacy, fully equipped kitchen and so one.

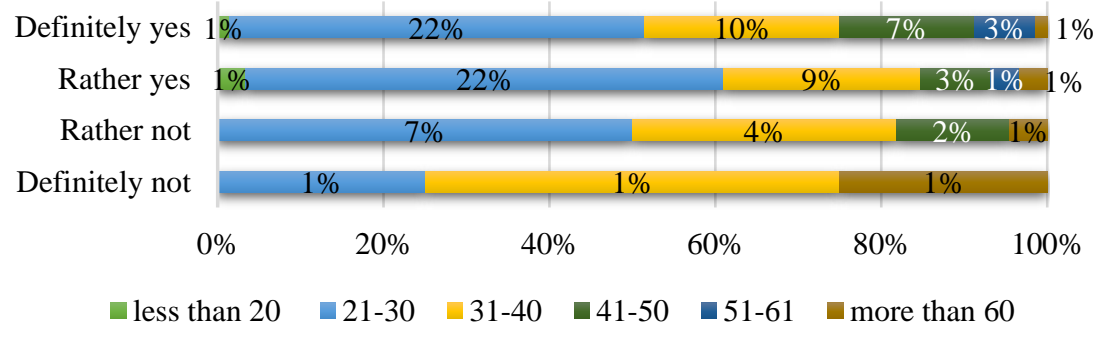

\section{Figure 3. Tourism development according to the age}

Source: Own elaboration, 2019

Respondents were also asked if they think that AirBnB helps to develop tourism in destination. 82\% said "Definitely yes" or "Rather yes", $18 \%$ said "Definitely no" or "Rather no". The next question focuses on the safety of AirBnB. 89\% of respondents consider AirBnB safe, but 11\% said "Rather not". We can guess that it might be because the location of the accommodation could be in a busy area or in not a very popular part of the city. Little distrust was recorded especially between ages 21-30 and also between ages 31-40.

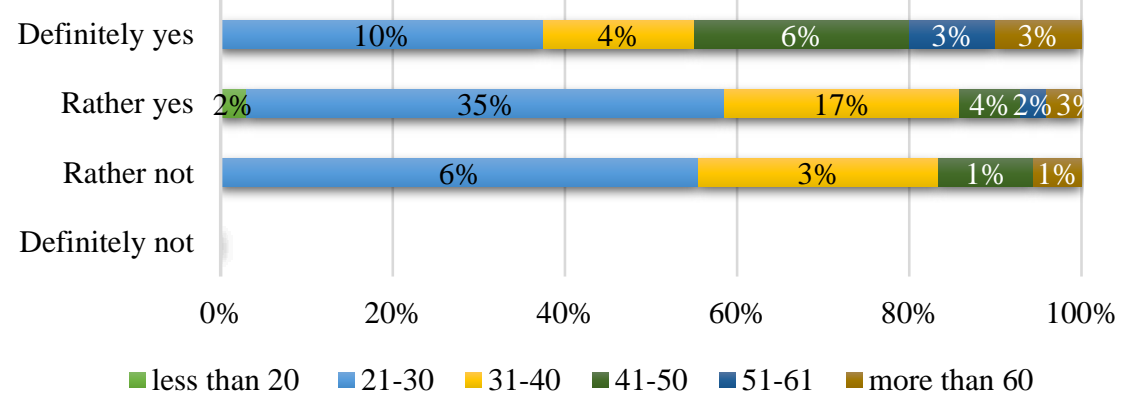

Figure 4. AirBnB safety according to the age

Source: Own elaboration, 2019 
The last question in this section was asking if AirBnB is turning mainly into business nowadays. $87 \%$ of respondents said "Definitely yes" or "Rather yes", $13 \%$ does not think that.

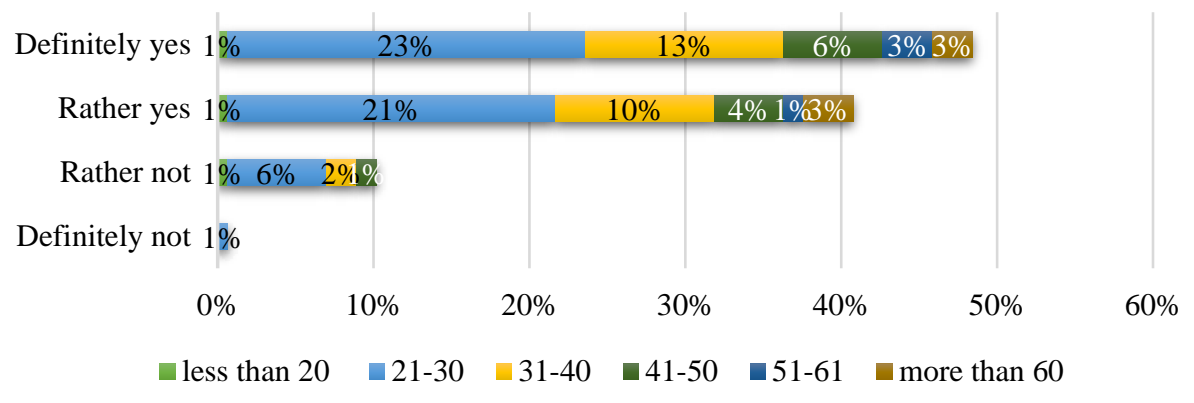

\section{Figure 5. AirBnB as business}

Source: Own elaboration, 2019

\section{The analysis of supply}

The analysis of supply is based on answers from respondents from Madeira, who offer their accommodation through AirBnB channel.

At the beginning, respondents were asked when they became a part of the rental community. 33\% of respondents answered the year 2017, 27\% answered 2016, 20\% said 2015 and $17 \%$ became a member earlier than 2015. The last $3 \%$ of respondents joined the community in 2018. It is obvious from the figure 6 , that the number of providers is growing with time and second thing we can see is, that males joined the joined AirBnB earlier than females. The biggest reason for joining the rental community was income (80\%). Meeting new people reach only $20 \%$ of answers. From the comparison between genders, it turned out that the reason for males was income with $94 \%$, and only for $6 \%$ males was the reason meeting new people. The situation is different with females. $64 \%$ of them started with renting because of the income, but $36 \%$ of females wanted to meet new people.

In the following question, providers were asked, what type of accommodation they provide. $90 \%$ of respondents provide an entire home and $10 \%$ provide a private room in their home. We can say that nearly the same ration was detected with visitor's preferences.

The following question focuses on income. The income from renting is the main income for $30 \%$ of providers, the rest $70 \%$ do not count renting as a main income, but just as an extra earning. We can see from the figure 6 , that the income from renting is the main income in most cases for self-employed people. 


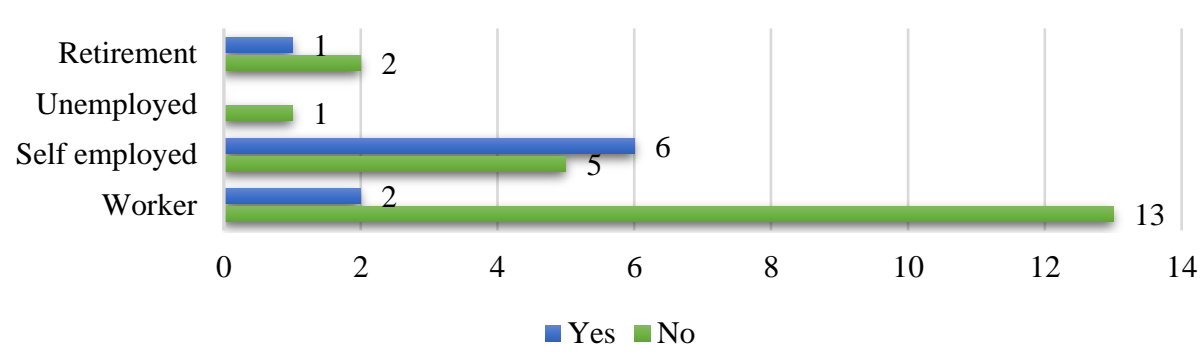

\section{Figure 6. Rental as the main income}

Source: Own elaboration, 2019

As visitors, providers were asked for their negative and positive experiences about renting. More than $50 \%$ of respondents did not face any negative experience, the rest mentioned, for example, rude clients, bureaucracy, the taxes and jealousy of the customers because of the host's home and also guests who do not speak any other language than their own and they expect the host to understand that language. Positive experiences are primarily meeting new interesting people from over the world, quick payment, reliability, presents from visitors and many bookings.

Next, people were asked if there is enough shared accommodation in Madeira. $70 \%$ of respondents answered "Definitely yes" or "Rather yes", $30 \%$ said "Rather not" or "Definitely not". In detailed evaluation, it is clear that people who answered "Rather not" or "Definitely not" were not even close about theirs guess how many Airbnb's are in Madeira in one of the previous questions. Their guesses were often lower than 1000.

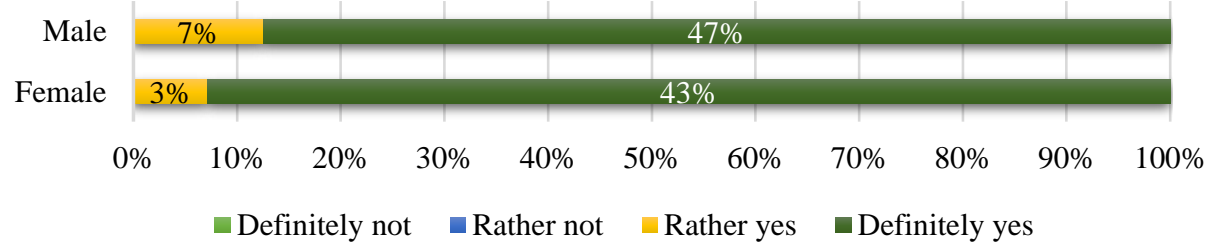

Figure 7. The development of tourism

Source: Own elaboration, 2019

The last question is focused on thoughts if this type of accommodation helps to develop tourism in Madeira. The results from this question are pretty one-sided. 90\% of providers said "Definitely yes" and 10\% said, "Rather yes". Nobody has doubts about this question. It is obvious that AirBnB helps to develop tourism in Madeira, but we can ask ourselves, when it is enough or even too much. There might be a thin border between developing tourism and destroying the city as you can read about AirBnB situation in literature overview at the beginning of this paper.

\section{Conclusion}

The main aim of this paper was to analyse the current state and identify the potential for the development of shared accommodation in Madeira island. The 
second goal was to identify barriers of its development based on the results of research about this type of accommodation and reduce them. Research could offer some answers on the main research question. Commercial focused of sharing accommodation is clear. The Airbnb become a business model instead of philosophy of travel and hosting.

Studying theoretical knowledge of sharing economy and more specifically shared accommodation shows that this topic is greatly popular these days in many different ways. Someone is supporter and perceives positively the idea of shared accommodation someone is the opposite. Supporters are mostly providers of accommodation because of extra income and travellers because of the opportunity to live more like local, reasonable prices and sometimes, uncommon types of accommodation. On the other hand, people who live in the area with many accommodation opportunities, in the city centre or have travellers next door are not very happy. Prices of rent are much higher, people on holiday are often noisier and the place is just crowded.

The research was assembled in a way that the demand and the supply of AirBnB can be compared. The supply was focused on specific destination, Madeira island, and the demand was focused on travellers from over the world. To gain more specific information, individual interviews were implemented.

Based on questionnaires it turned out that in many ways, answers of demand and supply are similar. Most respondents found out about AirBnB on the internet, the majority of both groups think that AirBnB is better than hotels and that AirBnB helps to develop tourism in the area but also that AirBnB is turning mainly into businesses and does not meet the main purpose of shared accommodation. The results also show that people are greatly influenced by reviews and without them, the chance of booking the accommodation is getting lower. Other answers show that most visitors prefer separated accommodation and most providers provide the entire home with full privacy, so it collaborate very well. The research did not show significant difference in answers between genders.

Respondents of demand shared their negative experiences such as noise, smell, not good communication with the host, not clean place but also positive experiences such as little gift, clean place, reasonable price, kind host etc. The negative findings were recorded as barriers of the development and some tips were suggested to providers, how to improve their offer. Tips were also suggested to visitors, how to behave when choosing and staying in AirBnB. Individual interviews helped to understand, why people prefer AirBnB rather than hotels and it is mostly because of privacy, the kitchen area and the unique experience.

There are limitations of the research. The research samples were not representative and results can't be generalized. There are need to continue in this type of research in follow up surveys and studied the topic more in detail. The timeliness is the second problem of research. The surveys were conducted before the covid-19 pandemic, that represent the usage of sharing economy state without macro impacts. 


\section{Acknowledgment}

This paper was supported by SGS grant SGS-2021-020 Changes in Economics and Marketing of Tourism by University of West Bohemia

\section{References}

1. Airbnb, (2018). About Us - Airbnb Press Room. Airbnb News. Airbnb. Retrieved from https://press.airbnb.com/en-uk/about-us

2. AirDNA. (c2015-2018). AirDNA MarketMinder. AirDNA: Short-Term Vacation Rental Data. AirDNA. Retrieved from https://www.airdna.co/vacation-rentaldata/app/us/california/san-francisco/overview

3. GfK, Czech Republic, (2017). Data.Brno. Analýza turistické poptávky města Brna. Retrieved from https://data.brno.cz/analyza-turisticke-poptavky-mesta-brna/

4. Krajcik, V., Kljucnikov, A., \& Rihova, E. (2019). Innovative Sharing Economy's Business Models in Tourism: Case of Airbnb in Prague. Marketing and Management of Innovations, 2, 108-117. http://doi.org/10.21272/mmi.2019.2-10

5. Heath, S., Davies, K., Edwards, G., \& Scicluna, R. (2017). Shared Housing, Shared Lives: Everyday Experiences Across the Lifecourse. Routledge.

6. Heckman, L. (2017). The Airbnb Story: How Three Ordinary Guys Disrupted an Industry. Made Billions....and Created Plenty of Controversy. Library Journal, 142(5), 126-126.

7. Hübscher, M., Schulze, J., zur Lage, F., \& Ringel, J. (2020). The Impact of Airbnb on a Nonturistic city. A case study of short-term rentals in Santa Cruz De Tenerife (Spain). Erdkunde, 74(3), 191-204. https://doi.org/10.3112/erdkunde.2020.03.03

8. Chamusca, P., Fernandes, J-R., Carvalho, L., \& Mendes, T. (2019). The role of Airbnb creating a "new"- old city centre: facts, problems and controversies in Porto. Boletín de la Asociación de Geógrafos Espanoles, 83, 2820, 1-30. http://doi.org/10.21138/bage.2820

9. Shatford, S. (c2015-2018). The Biggest Airbnb Vacation Rental Cities in The World AirDNA. AirDNA: Short-Term Vacation Rental Data \&amp; Analytics. AirDNA. Retrieved from https://www.airdna.co/blog/biggest_airbnb_cities_in_the_world

10. Siuskaite, D., Pilinkiene, V., \& Zvirdauskas, D. (2019). The Conceptualization of the Sharing Economy as a Business Model. Engineering Economics, 30(3), 373-381. https://doi.org/10.5755/j01.ee.30.3.21253

11. Statista, (2019). Airbnb - Get the report with graphs and tables on statista.com!. Retrieved from: https://www.statista.com/study/24578/airbnb-statista-dossier/

12. Stemler, A. (2016). BETWIXT AND BETWEEN: REGULATING THE SHARED ECONOMY. Fordham Urban Law Journal, 43(1), 1-39.

13. Sundararajan, A. (2016). The sharing economy: the end of employment and the rise of crowdbased capitalism. Cambridge, Massachusetts: The MIT Press.

14. Surugiu, C., Surugiu, M., \& Mazilescu, R. (2019). SHARING ECONOMY, ICT AND DIGITAL MARKETING IMPACT ON THE RECENT TOURISM DEVELOPMENTS. Hyperion International Journal of Econophysics, 12(1), 167-175 